\title{
Effect of Nursing Intervention on Nurses' Knowledge and Practice Regarding Cataract Surgery
}

\author{
Amira Mohamed Abdel Azeem ${ }^{1}$, Wafaa H. Abdullah², Omima Said M. \\ H. Shehata ${ }^{3}$, Amin Faisal Ellakwa ${ }^{4}$ \\ ${ }^{1}$ B.Sc. Nursing Science, ${ }^{2}$ professor of Medical Surgical Nursing, ${ }^{3}$ Assistant Professor of \\ Medical Surgical Nursing, Faculty of Nursing, Menoufia University, ${ }^{4}$ Assistant Professor of \\ Ophthalmology, Faculty of Medicine, Menoufia University.
}

\begin{abstract}
Cataract is the second cause of visual impairment and the first cause of blindness globally. So, inadequate nursing interventions lead to serious complications for patients with cataract surgery. Purpose of the study: was to examine the effect of a nursing intervention on nurses' knowledge and practice regarding cataract surgery. Design: a quasiexperimental research design was utilized. Setting: the current study was carried out at Ophthalmology Department in Menoufia University Hospital and El Ramad Hospital in Shebin El-Kom. Sample: a purposive sample of 25 nurses was included. Instruments: two instruments were used for data collection: a self-administered questionnaire for nurses knowledge and an observational checklist for nurse's practice. Results: The mean age for nurses was $36.8 \pm 8.94$, all nurses were married females with more than 3 years of clinical experiences. There was an improvement in total mean score of nurses' knowledge from $23.60 \pm 2.87$ pre intervention to $35.92 \pm 3.85$ post intervention and after one week to $39.24 \pm 2.04$ as a follow up intervention. Also, there was an improvement in the total nurse's practice score from $100.64 \pm 17.77$ pre intervention to $244.56 \pm 23.65$ post intervention and after one week to $250.96 \pm 20.86$ as a follow up intervention. Conclusion: nurse's knowledge and practice improved after implementing nursing intervention. Recommendation: educational nursing interventions using the same educational methods should be carried out for nurses in ophthalmology settings to improve their knowledge and practices regarding cataract surgery.
\end{abstract}

Key words: Nursing intervention, Knowledge, Nursing Practice, Cataract.

\section{Introduction}

Cataracts are one of the serious eye problems, the second leading cause of visual impairment and the first cause of blindness globally. It is the most principal cause of blindness in people worldwide. Cataract accounting for approximately $42 \%$ of all cases of blindness in all nations. It is occurring in individuals aged 50 and older. If left untreated, cataract can eventually progress to severe visual impairment or even blindness (Bailey \&Thompson, 2016).

Cataract is the eye condition in which the lens of the eye becomes dense and cloud. Depending on its size and location, it can interfere with normal vision (American Optometric Association, 2019). Most cataracts are due to age-related changes in the lens of the eye that make it cloudy or opaque. Rarely, cataracts are present at birth or develop shortly after. However, there are risk factors that contribute to development of cataracts, including, diabetes mellitus, certain medications as: corticosteroids chlorpromazine and other phenothiazine-related medications. Also, high blood pressure, unprotected exposure to ultraviolet radiation and cancer treatments could be risk factors for developing of cataract (Bailey, Lee \& Heiting, 2018).

Common symptoms of cataracts include blurry vision, trouble seeing at night, seeing colors as faded, increased sensitivity to glare of the sun or other 


\section{Effect of Nursing Intervention on Nurses' Knowledge and Practice Regarding Cataract Surgery}

bright lights, driving becomes more difficult, particularly at night, halos surrounding lights, double vision in the affected eye and a need for frequent changes in prescription glasses. Vision loss due to cataracts is usually very gradual as cataract cause vision to worsen, making it especially difficult to see fine details clearly (National Eye Institution, 2017).

Prevention of cataract is a very important and vital role of the ophthalmic nurse to reduce the risk of developing cataract through educate the patient to protect eyes from ultraviolent rays by wearing sunglasses outside, have regular eye exams, stop smoking, eat fruits and vegetables that contain antioxidants, maintain a healthy weight, keep diabetes and other medical conditions in check regularly (Jacobs, 2016).

Treatment of cataracts, using eye drop or other treatments that claim don't remove cataract. If symptoms are not affecting on the performing activities of daily living, just need stronger eyeglasses prescription, magnifying lenses, or sunglasses with an anti-glare coating. Surgery is recommended when cataracts be a barrier of a daily living activities, such as reading or driving. It's also performed when cataracts interfere with the treatment of other eye problems (National Eye Institute, 2019).

Cataract surgery is the only option to cure from cataract. The cataract surgery is one of the safest and successful surgical procedures performed today; more than $95 \%$ of surgeries are successful with fewer than $5 \%$ of cases experiencing complications such as inflammation, bleeding, infection and retinal detachment (Royal national institute of blind people, 2019).

The nursing intervention starts from the preoperative period and extends to the postoperative period as well as discharge instructions. The nurses should assess the patient's preoperative basic needs and assist to meet these needs. Preoperative intervention has proven beneficial in decreasing postoperative complications and length of stay as well as positively influencing recovery (Rabinovitach, 2017).

Previous studies recommended that educational nursing interventions is effective methods to enhance the clinical outcomes of the patient with cataract, improve the quality of life and assist the patient to meet needs and perform daily living activities effectively (American College of Eye Surgeons, 2019).

\section{Significance of the Study}

Epidemiological studies have indicated that cataracts affect more than 22 million American aged 40 or older (Robertson, 2019). In USA, there is a yearly new incidence of about 400.000 new cases (American academy association of ophthalmology, 2015). In Egypt,

the prevalence of low vision for all ages is $47.9 \%$ of the population while who associated with cataract that being the major cause of blindness is $54.8 \%$ (Hegazy, Ragheb, Elsayed and Rashad, 2012). According to statistical record of El-Ramad hospital (2018) about 3000 surgeries are conducted to remove white water for patients with cataract surgery in El Ramad Hospital and about 1200 cases are annually subjected for cataract related surgery at ophthalmology department in Shibin El Kom Menoufia University Hospital (Statistical record of Menoufia University Hospital of Ophthalmology, 2018). As nurses have a major role in all aspects of cataract surgery, this study was done to examine effect of nursing intervention on nurses' knowledge and practice regarding cataract surgery. 


\section{Effect of Nursing Intervention on Nurses' Knowledge and Practice Regarding \\ Cataract Surgery}

\section{Purpose of the Study}

The purpose of the current study was to examine effect of nursing intervention on nurses' knowledge and practice regarding cataract surgery.

\section{Research Hypothesis:}

- Nurses who receive nursing intervention has a higher level of knowledge than pre nursing intervention.

- Nurses who receive nursing intervention has a higher level of practice than pre nursing intervention.

\section{Operational definition:}

- Nursing intervention: defined as teaching instructions for development of nursing practice for cataract patient which include teaching about eye anatomy and physiology, cataract (definition, causes, risk factors, signs \& symptom, types, prevention and cataract surgery), nursing care before and after cataract surgery and patients' discharge instructions. It was assessed using instrument I developed by researcher.

- Nurse's practice: is defined as the nursing care given to the cataract patients (e.g. instillation of eye drops, eye ointment, change eye dressing, etc...) before and after cataract surgery. It was assessed using instrument II developed by researcher.

\section{Methods}

\section{Research design:}

A quasi experimental research design was utilized to achieve the purpose of this study.

\section{Research Setting:}

The study was carried out at ophthalmology Department in Menoufia University Hospital and El
Ramad Hospital in Shebin El-Kom, Menoufia Governorate, Egypt.

\section{Sample:}

A purposive sample of 25 nurses was selected for the current study.

\section{Instruments:}

Self-administered questionnaire, it was developed by the researcher to assess sociodemographic and knowledge of the nurses based on a review of related literature, 2018). It was written in English and contained two parts as the following.

- Part one: Social characteristics of the nurse: it was used to collect data about the following: age, gender, marital status, educational level, years of clinical experiences and training courses in ophthalmology.

- Part two: knowledge assessment: It included questions to assess nurse's knowledge before and after implementation of educational nursing intervention. It included 9 questions about anatomy and physiology of the eye (e.g. eye layers, orbit, etc..), 10 questions about cataract (e.g. definition, causes, types, etc.), 6 questions about nursing intervention (e.g. relieving postoperative pain, prevention of infection, etc...), 6 questions about pre discharge instructions (e.g. instillation of eye drops, ointments, etc...),

The reliability of self-administered questionnaire was reported in a study of 25 nurses. Internal consistency was evaluated using Cronbach's alpha for the entire PFS-R (31 items) was 0.85 .

\section{Total Scoring system:}

Scoring system for each question:

\begin{tabular}{|l|c|}
\hline \multicolumn{1}{|c|}{ Answer } & Score \\
\hline $\begin{array}{l}\text { Incorrect answer or don't } \\
\text { know }\end{array}$ & 0 \\
\hline Incomplete correct answer & 1 \\
\hline Complete correct answer & 2 \\
\hline
\end{tabular}




\section{Effect of Nursing Intervention on Nurses' Knowledge and Practice Regarding Cataract Surgery}

Nurse's knowledge was clarified on a 3-point scale consisting of complete correct answer, incomplete correct answer and incorrect answer or don't know. Score of 2, 1 and zero were assigned for the previous points respectively. The total score ranged from zero to 62. The higher the score, the higher the level of knowledge \& vice versa.

The total score of knowledge was categorized into:

- A score less than $60 \%$ denoted poor knowledge.

- A score from $60 \%$ to $75 \%$ denoted fair knowledge

- A score more than $75 \%$ denoted good knowledge.

II. Nurses Practices Observation Checklist, this tool was developed by the researcher to examine nurse's practice for the care provided to patients after cataract surgery because the patient admitted at the day of surgery and perform preoperative care at home. The hospitalized general preoperative care to the patient as (blood sugar control -blood pressure measuring, etc....) and also to assess nurse's practice away from visits and rounds while instilling eye drops ( 15 items), applying eye ointment (12 items), changing eye dressing (10 items), performing eye care with maintaining infection control (13 items), using non-pharmacological methods to reduce pain such as relaxation massage (7 items), tense \& relax exercise (71 items), deep breathing exercise ( 7 items). The reliability of practices observation checklist was reported in a study of 25 nurses. Internal consistency was evaluated using Cronbach's alpha for the entire PFS-R (135 items) was 0.81 .

Scoring system: -

Scoring system for each item:

\begin{tabular}{|l|c|}
\hline \multicolumn{1}{|c|}{ Practice } & Score \\
\hline Not done & 0 \\
\hline Done incompletely & 1 \\
\hline Done completely & 2 \\
\hline
\end{tabular}

The total score ranged from zero to 270. The higher the score, the higher the nurses' practices level $\&$ vice versa.

The total score of nurses' practices were categorized into:

- A score less than $60 \%$ denoted unsatisfactory practice.

- A score from $60 \%$ to $75 \%$ denoted partial satisfactory practice.

- A score more than $75 \%$ denoted satisfactory practice.

Written approval: Permission to carry out the study was taken from responsible authorities after explanation of the purpose of the study.

Ethical Consideration: Approval was obtained from the Faculty of Nursing, Menoufia University, Ethical and Research Committee. A written consent was obtained from all nurses for their acceptance to participate in the current study after explanation of the purpose of the study. Each nurse was reassured that any information obtained would be confidential and would only be used for the study purpose. The researcher emphasized that participation in the study was entirely voluntary and anonymity of the nurses were assured through coding of data. Nurses were also informed that refusal to participate in the study wouldn't affect on their work.

Validity: All the tools of the study were developed by the researchers after reviewing the relevant literature. They were tested for content validity by five experts 4 (assistant professors or professors)in the field of medical surgical nursing, Faculty of Nursing, 


\section{Effect of Nursing Intervention on Nurses' Knowledge and Practice Regarding \\ Cataract Surgery}

Menoufia University and one ophthalmologist from Faculty of Medicine, Menoufia University (assistant professor or professor) and modifications were done to ascertain the relevancy and completeness.

Pilot study: - A pilot study was conducted on $10 \%$ (3 nurses) of the study sample prior data collection to test the feasibility, clarity and applicability of the instrument. Then, necessary modifications were carried out. The sample used was excluded.

\section{Procedure:}

- An official letter was submitted from the Dean of the Faculty of Nursing, Menoufia University to the directors of selected settings explaining the purpose and methods of data collection

- Data collection extended over a period of 6 months (from the beginning of July 2019 to the end of December 2019).

- Nurses' knowledge was assessed using the self-administered questionnaire (instrument one). This was followed by observing their practices for providing required nursing care using instrument two.

- Based on analysis of the collected data, pertinent literature and apparent needs of nurses, the researcher developed educational nursing interventions for nurses to care of cataract patient's surgery

- Each nurse received 3 theoretical sessions and 2 practical sessions. Each session ranged between 45 to 60 minutes.

- Nurses were divided into 5 groups. Each group contained 5 nurses. The teaching methods involved lectures, group discussions as well as demonstration and return demonstration (for practical parts). The utilized teaching media included illustrative pictures, videotapes and handouts.

Theoretical sessions:- it was included 3 session which

- The first teaching session: basic knowledge regarding anatomy, physiology of eye in addition to cataract disease, definition, causes, risk factors, types, signs \& symptoms, diagnosis and prevention.

- The second teaching session: knowledge regarding cataract surgery indications, most common techniques, complications, nursing intervention before cataract surgery such as assess the visual acuity before surgery, activities which may increase intraocular pressure as (coughing, lifting heavy objectives, bending over at the waist) and after cataract surgery such as proper position after surgery, nurse role for relieving postoperative pain, prevention of infection, signs \& symptoms on infected eye, diet to help healing and postoperative complications.

- The third teaching session: knowledge regarding predischarge instruction for patient and their families regarding instilling eye drops and ointment, wearing eye shield, protection of the eye, precautions to prevent infection, food regimen to reduce straining and constipation, exercise, avoiding heavy lifting and unusual symptoms, follow-up.

Practical sessions: it was included 2 session which

- The first practical session: was included practice regarding demonstration of instilling eye drops, applying ointment, changing eye dressing and performing eye care with maintaining infection control.

- The second practical session: was included practice regarding 


\section{Effect of Nursing Intervention on Nurses' Knowledge and Practice Regarding \\ Cataract Surgery}

demonstration of measures for relieving postoperative pain, using non-pharmacological methods to reduce pain such as relaxation massage, tense \& relax exercise and deep breathing exercise.

- Evaluation of nursing intervention effects on nurses' knowledge and practice, was performed by using the same assessment instruments. each nurse was evaluated immediately after educational nursing intervention (post-test) and one week after the interventions (follow-up).

\section{Statistical analysis:}

The data collected were tabulated and analyzed by SPSS (statistical package for the social science software) statistical package version 20 on IBM compatible computer. Descriptive statistics were expressed as mean and standard deviation $(\mathrm{X} \pm \mathrm{SD})$ for quantitative data or number and percentage (No \& \%) for qualitative data. F- Mann-Whitney test (nonparametric test and ANOVA test were used. If P-value $>0.05$ to be statistically insignificant. no statistically significant difference was calculated, if $\mathrm{P}$-value $\leq 0.05 \mathrm{a}$ statistically significant difference was considered If $\mathrm{P}$-value $\leq 0.001$, there is a very highly statistically significant difference.

\section{Results}

Table (1) showed the general characteristics of studied nurses: It was revealed that all nurses in the study sample were females, with age ranging between 26 and 56 years. The majority of the study sample was married. Regarding to educational level, it was observed that about $64 \%$ were highly educated and $36 \%$ had secondary school education. As regards years of clinical experience, all nurses experienced more than 3 years in ophthalmologic department. Regarding to training courses only $44 \%$ of nurses reported having previously attended -up. There was highly statistically significant difference regarding to nurses' knowledge related to eye anatomy, cataract disease and nursing role in cataract surgery preintervention, post- intervention and follow up with $\mathrm{P}$ value $<0.001$.

Table (2) showed the distribution of knowledge of the studied nurses' group. It was observed that there was an improvement in mean total nurses' knowledge score about eye anatomy, cataract disease and nursing role regarding cataract surgery from 23.60 \pm 2.87 pre intervention to $35.92 \pm 3.85$ $\& 39.24 \pm 2.04$ post intervention and one week after intervention as a follow up respectively. There was highly statistically significant difference regarding to nurses' knowledge related to eye anatomy, cataract disease and nursing role in cataract surgery preintervention, post- intervention and follow up with $\mathrm{P}$ value $<0.001$

Figure (1) illustrated that the majority of nurses had an improvement in their level knowledge regarding to eye anatomy, cataract

disease and nursing role in cataract surgery post - intervention $(72 \%$ had a good level of knowledge, $28 \%$ had a fair level of knowledge post intervention and after one week of intervention. As well as, there was a very highly statistically significant difference related to level of nurses' knowledge post intervention and after one week of intervention in follow up as compared with pre- intervention with $P$ value $<0.001$.

Table (3) showed means of the levels of nursing practice on pre, post and follow up interventions. It was cleared that there was an improvement in mean total nurses' practice score related to instilling eye drops, applying ointment, 


\section{Effect of Nursing Intervention on Nurses' Knowledge and Practice Regarding \\ Cataract Surgery}

change eye dressing, eye care and infection control, relaxation massage, tense and relax exercise for eye, deep breath exercise and nonpharmacological methods for pain control from $100.64 \pm 17.77$ post intervention to $250.96 \pm 20.86$ one week after intervention. There was a very highly statistically significant difference related to differences in nursing practice about instilling eye drops total score, applying ointment score, change eye dressing score, eye care and infection control score, relaxation massage score, tense and relax exercise score, deep breath exercise total score and nonpharmacological methods for pain control score pre- intervention, postintervention and follow up with $\mathrm{P}$ value $<0.001$.

Figure (2) illustrated that all of nurses had an improvement in the level of nurses' practice post - intervention and one week after intervention, $96 \%$ had a good level of practice and $4 \%$ had a fair level of practice as compared with pre- intervention $100 \%$ had a poor level of practice.

Table (1): General characteristics of studied nurses.

\begin{tabular}{|c|c|c|}
\hline & $\begin{array}{c}\text { No. } \\
(\mathrm{N0}=25)\end{array}$ & $\%$ \\
\hline $\begin{array}{l}\text { Age (Y): } \\
\text { Mean } \pm \text { SD } \\
\text { Range }\end{array}$ & & $\begin{array}{c}36.8 \pm 8.94 \\
26-56\end{array}$ \\
\hline $\begin{array}{c}\text { Level of education: } \\
\text { - Diploma } \\
\text { - } \text { Bachelor }\end{array}$ & $\begin{array}{c}9 \\
16\end{array}$ & $\begin{array}{l}36.0 \\
64.0\end{array}$ \\
\hline $\begin{array}{c}\text { Training courses: } \\
\text { - Yes } \\
\text { - No }\end{array}$ & $\begin{array}{l}11 \\
14\end{array}$ & $\begin{array}{l}44.0 \\
56.0\end{array}$ \\
\hline
\end{tabular}

N.B: All nurses were married females with more than 3 years' clinical experience

Table (2): Distribution of knowledge for nurses pre, post and follow up interventions.

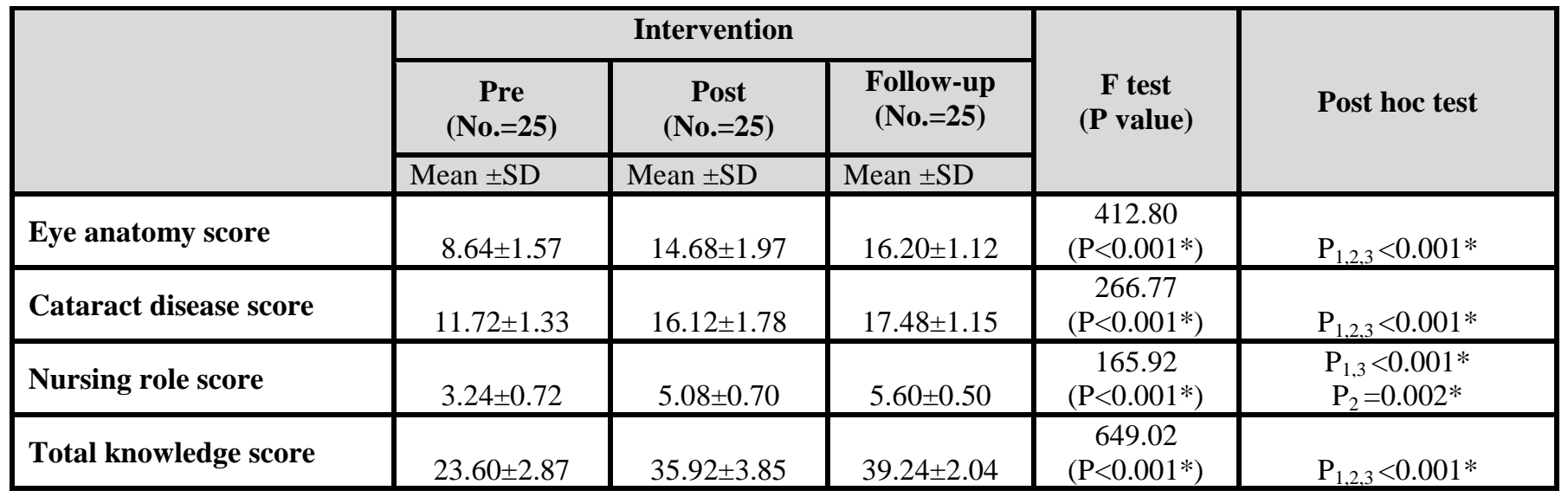

F test: Repeated measures ANOVA ${ }^{*}$ : significant, $\mathrm{P}_{1}$ : Pre vs. Post, $\mathrm{P}_{2}$ : Pre vs. Follow-up, $\mathrm{P}_{3}$ :

Post vs. Follow-up; ${ }^{\wedge}$ : Fishers; exact test 


\section{Effect of Nursing Intervention on Nurses' Knowledge and Practice Regarding Cataract Surgery}

Figure (1) Levels of knowledge of the studied nurses on pre, post and follow up interventions.

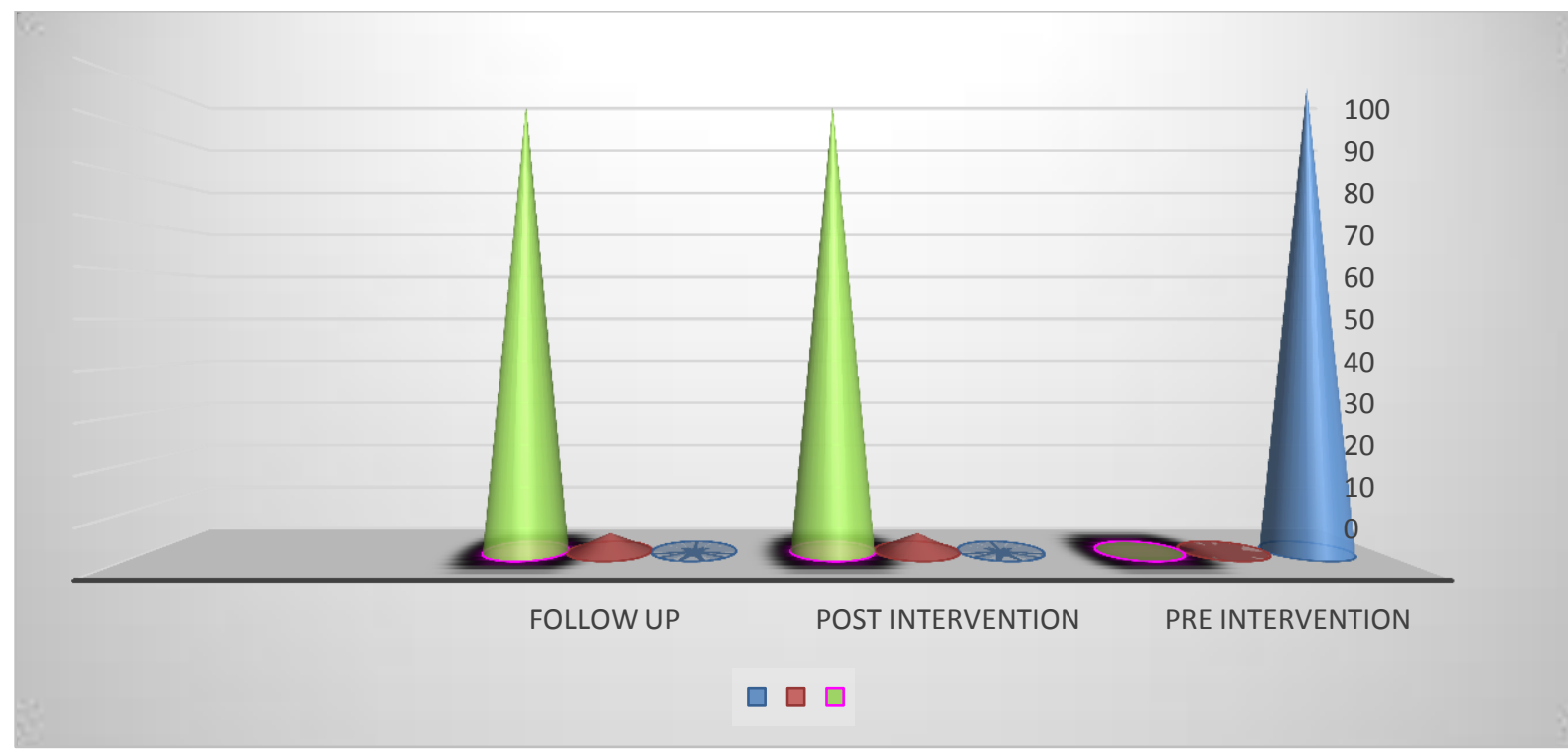

Table (3): Distribution of Nursing Practices Pre, Post and Follow up Interventions

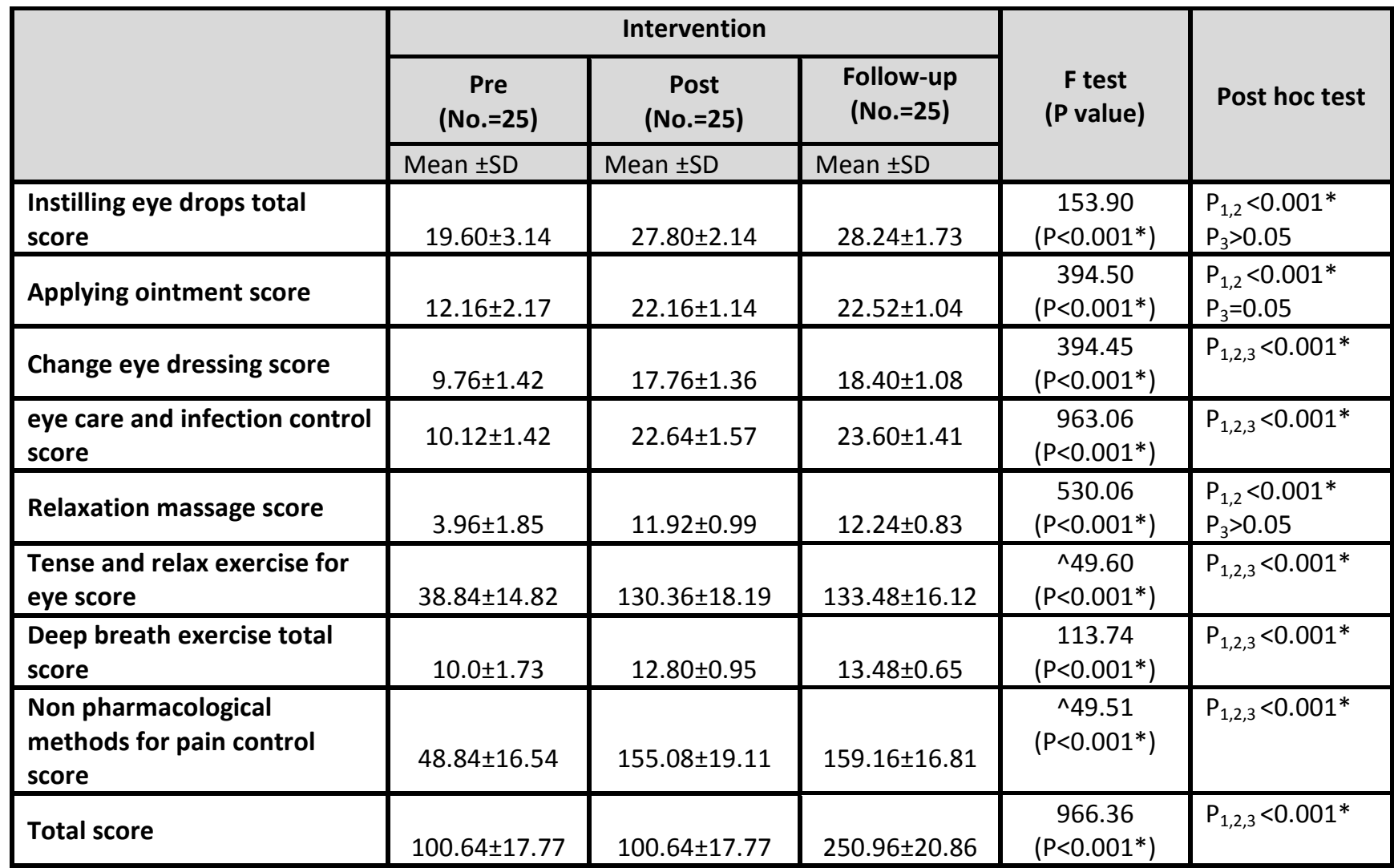

F test: Repeated measures ANOVA *: significant, $P_{2}$ : Pre vs. Post, $P_{2}$ : Pre vs. Follow-up, $P_{3}$ : Post vs. Follow-up^^: Friedman test

Figure (2): Levels of Nurses' practice of the studied nurses on pre, post and follow up interventions. 


\section{Effect of Nursing Intervention on Nurses' Knowledge and Practice Regarding \\ Cataract Surgery}

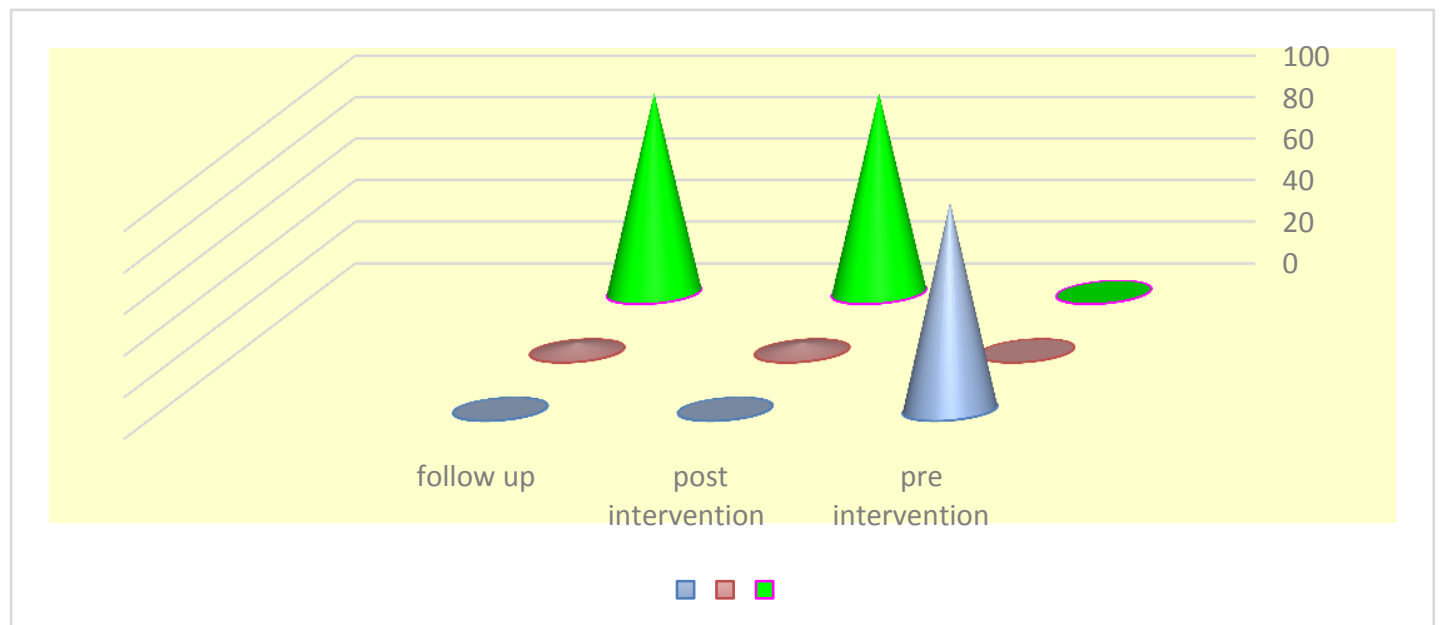

\section{Discussion}

Cataract surgery considers one of the most common cost-effective and successful surgical procedures that is performed worldwide. With a globally aging population, the number of cataract surgeries performed is expected to rise, requiring better staff preparation to develop more cost-effective and efficient methods of caring for these patients and improve outcomes, only few studies demonstrated the effectiveness of nursing intervention on patient undergoing cataract surgery. In this respect, the main concern of the present study was to examine effect of nursing intervention on nurses' knowledge and practice regarding cataract surgery.

I. First hypothesis, nurses who receive nursing intervention will have a higher level of knowledge than pre nursing intervention.

The study findings clarified that nurses' knowledge was generally low before implementation of the intervention, particularly in relation to anatomy of the eye, cataract disease and more importantly of the role of the nurse in the care for cataract patients with total mean knowledge score23.60 \pm 2.87 .

From the researcher point of view, the knowledge deficit about anatomy of the eye and cataract disease can affect the role of the nurse. It could be attributed to the unavailability of lectures related to ophthalmology in nursing courses. This finding is in agreement with Belal (2004) and Taha et.al, (2018) who reported that nurses' knowledge of the anatomy and physiology of the eye was unsatisfactory. Moreover the current study finding was in agreement with Mafwiri et al, (2014), El Shafaey \& Basal, (2018) and Kareem \& Hamza (2019). They revealed that, the majority of the studied nurses had fair level of knowledge score regarding eye care after attending training programs for nurses to improve and update nurses 'knowledge. Also, the current study is in line with ElMowafi, (2019) who showed that the level of knowledge was improved after immediate implementation of the training program than before.

Additionally, this justification goes in line with Mafwiri et.al, (2014) who mentioned that after implementation of educational program, nurses had significantly showed much higher mean knowledge score than the score before the implementation of educational program related eye care that demonstrated of the study in Tanzania.

This improvement indicates the positive impact of the intervention on nurses' knowledge, and this was further confirmed through multi analysis which identified the intervention as a significant independent positive predictor of the improvement in nurses' knowledge. A similar success of an intervention in improving nurses' knowledge about eye care was 


\section{Effect of Nursing Intervention on Nurses' Knowledge and Practice Regarding Cataract Surgery}

demonstrated in a study in Taha et. al, (2018). Perhaps the utilized teaching methods and media attributed to the success of the program.

II. Second hypothesis, nurses who receive nursing intervention will have a higher level of practice then pre intervention.

the present study revealed that; there was a major deficiency in postoperative nurses' practice as regards to instilling eye drops, applying ointment, changing eye dressing, performing eye care and infection control, practice of measures for relieving postoperative pain, using nonpharmacological methods to reduce pain such as relaxation massage, tense \& relax exercise, deep breathing exercise for cataract patients before implementation of intervention than after the intervention. this This result agrees with Ahmed (2007) and El Shafaey \& Basal, (2018) that also found a major deficiency in nurses' practice related to post-operative care for cataract patients before implementation of the guidelines, such as the application of eye ointment, eye dressing using infection control, and non-pharmacologic pain relief. This finding could be attributed to lack of training programs and shortage of handling opthalmology nursing in nursing programs. On the other hand the result disagree with El Shafaey \& Basal, (2018) who found that the majority of the studied nurses had fair level of practice score pre implementation of teaching program while the score was good immediately post- implementation of teaching program. From the researcher point of view, the difference could be attributed to the difference in settings and policies that allow the establishment of training programs for nurses

\section{Conclusions:}

Based on the findings of the current study, it can be concluded that implementing nursing intervention of care for patients undergoing cataract surgery had a positive effect and improvements in nurses' knowledge and practice.

\section{Recommendations:}

Ophthalmic nurses should receive periodic training programs to improve, update, refreshing their knowledge and practice regarding cataract. Replication of the study on a large sample size and with long term follow up can help in generalized the results on other clinical areas.

\section{References}

Ahmed M, (2007): Assessment of Patients Needs, Nurses Role in Caring Children with Ophthalmic Disorder, Unpublished Master Thesis, Faculty of Nursing, Ain Shams University. Retrieved on : 24 February, (2020).

American academy Association of ophthalmology, (2015). Eye Health Statistics. Available at: https://www.aao.org/newsroom/eyehealth-statistics. Retrieved on: 22 September, (2019).

American College of Eye Surgeons, (2019): Educational nursing intervention. Available at: https://www.aoa.org/patients-andpublic/eye-and-visionproblems.

Retrieved on: 23 July, (2019).

American Optometric Association, (2019): Causes of Cataract disease. Available at: https://www.aoa.org/patients-andpublic/eye-and-vision problems/glossary-of-eye-and-visionconditions/cataract. Retrieved on: 23 July, (2019).

Bailey G and Thompson V (2016): Cataract diseases. Available at: www.allaboutvision.com. Retrieved on: 23 July, (2019).

Bailey G., Lee J., and Heiting G, (2018): The impact of cataract surgery on quality of life. Available at: http://blockrecords.icu/ts/page. php?id=6847. Retrieved on: 23 December, (2019).

Belal S., Ibrahim M., El SenosyT, and Hegazy, S. (2004): Post-operative self- 
careguide for patients with intraocular surgery.Master thesis. Faculty of Nursing, Ain ShamsUniversity. Retrieved on: 14 February, (2020).

El Shafaey M and Basal A, (2018). Effect of Implementing Teaching Program on Knowledge and Practice of Nurses and Clinical Outcomes of Patients Post Cataract Surgery .IOSR Journal of Nursing and Health Science (IOSRJNHS) e- ISSN: 2320-1959.p- ISSN: 2320-1940 Volume 7, Issue 3 Ver. X (May-June .2018), PP 60-70. Available at: www.iosriournals.org. Retrieved on: 24 February, (2020).

El-Mowafi $\mathrm{H}$ "Effect of Training Program on Performance of Nurses Caring for Patient with Negative Pressure Wound Therapy" .IOSR Journal of Nursing and Health Science (IOSRJNHS), vol. 8, no.01, 2019, pp. 31-35. Retrieved on: 23 December, (2019).

Hegazy S. M, Ragheb M, Elsayed N.O, and Rashad M. A, (2012): Health Needs Managements Among Patients Undergoing Day Case Cataract Surgery. Proposed protocol, life science Journal; 9(2): 1316-1327. Available at: http://www.lifesciencesite.com. Retrieved on: 29 May, (2018).

Jacobs DS, (2016): Cataract in adults. Available at: http://www.uptodate. com/home. Retrieved on: 29 September, (2019).

Kareem M and Hamza R, (2019). Effectiveness of Educational Program on Nurses' Knowledge regarding Pre and Post-Operative Nursing Management in Indian Journal of Public Health Research and Development - January 2019 DOI: 10.5958/0976-5506.2019.00186.4 Available at: https://www.researchgate.net/public ation/331251573. Retrieved on: 23 December, (2019).
Mafwiri M., Kisenge R., and Gilbert C. E. (2014): A pilot study to evaluate incorporating eye care for children into reproductive and child health services in Dar-es-Salaam, Tanzania: a historical comparison study. BMC Nurs.;13:15. Retrieved on : 19 February, (2020).

National Eye Institute, (2019): Cataract disease. Available at: https://nei.nih. gov/health/cataract/cataract facts. Retrieved on: 29 September, (2019).

National Eye Institution, (2017): Facts About Cataract. Available at :https://nei.nih.gov/ health/cataract. Retrieved on: 29 September, (2019).

Rabinovitch, (2017): Preoperative care of cataract. Available at: www.northtorontoeyecare.com/catar act/pre-operative-instructions. Retrieved on :19 October, (2019).

Robertson S (2019): Cataract Epidemiology. Available at: https://www.news-medical.net. Retrieved on :19 October, (2019).

Royal national institute of blind people, (2019): Cataract history Available at: https://www.news-medical.net. Retrieved on: 23 November, (2019).

Statistical record of El- Ramad hospital statistical record of Ophthalmology, (2018) Statistical record of Menoufia University Hospital of Ophthalmology, (2018)

Taha N., and Abd Elaziz N, (2018) . Effect of Nursing Intervention Guidelines on Nurses' Role, Patients' Needs, and Visual Problems Post Cataract Surgery. American Journal of Nursing Science 2015; 4(5): 261-269 Published online September 2, 2018 http://www.sciencepublishinggroup.c om/i/ajns) doi: 10.11648/j.ajns.20150405.13 ISSN: 2328-5745 (Print); ISSN: 2328-5753. Retrieved on: 11 February, (2020). 